\title{
Detecção molecular de vírus da bronquite infecciosa em plantéis de avós, matrizes e frangos de corte no Rio Grande do Sul e Mato Grosso
}

\author{
Molecular detection of infectious bronchitis virus in flocks of grandmothers, mothers and broiler \\ chicken in Rio Grande do Sul and Mato Grosso
}

Bárbara Nascimento ${ }^{\mathrm{I}}$ Juliana Comerlato $^{\mathrm{I}}$ Fernando Rosado Spilki ${ }^{\mathrm{I}}$

\section{RESUMO}

O vírus da Bronquite Infecciosa das galinhas (VBI) pertence ao grupo 3 da família Coronaviridae e é o causador de desordens respiratórias e renais em frangos de corte. A vacinação com vacinas vivas é praticada em matrizes e avós e muitas vezes também nos plantéis destinados ao abate. As vacinas utilizadas no Brasil são usualmente do sorogrupo Massachusetts e baseadas nas amostras H120 e H52. É comum que após a vacinação o vírus vacinal seja detectado por isolamento em ovos embrionados ou por métodos moleculares por até 4 semanas. Após essa data, normalmente, não há detecção de vírus e o VBI, quando encontrado, pode representar recirculação do vírus vacinal no plantel ou a introdução de uma nova cepa do vírus. No presente estudo, para avaliar a circulação do vírus em plantéis de frangos e reprodutoras nos estados do Rio Grande do Sul e Mato Grosso do Sul, foram coletadas 240 traqueias e rins de aves de 48 plantéis, sendo (20 exemplares/4 plantéis) de avós, (80 exemplares/16 plantéis) de matrizes e (140 exemplares/28 plantéis) de frangos de corte, as quais foram analisadas em misturas de cinco amostras. Todos os animais eram vacinados e as amostras foram coletadas ao redor de 2 a 48 semanas após a vacinação. A presença de VBI foi determinada com auxílio de uma reação em cadeia da polimerase tipo nested, direcionada ao gene da proteína 51 , padronizada neste estudo. Das 48 amostras testadas, 14 resultaram positivas: cinco foram oriundas de aves vacinadas há menos de quatro semanas na data da coleta e nove eram de amostras de aves vacinadas há mais de quatro semanas, o que pode ser devido à recirculação do vírus vacinal ou mesmo introdução de vírus selvagem nos plantéis.

Palavras-chave: bronquite infecciosa das galinhas, VBI, nested-PCR, avós, matrizes.

\begin{abstract}
Infectious bronchitis virus (IBV, Avian coronavirus) from chickens belongs to group 3 of the family Coronaviridae and causes respiratory and renal disorders in broilers. Vaccination using live vaccines is generally performed in mothers and grandmothers, as well as often in flocks for slaughter. The vaccines used in Brazil are usually from serogroup Massachusetts and based on standard samples of the virus at passages $\mathrm{H} 120$ and H52. It is common that after vaccination the vaccine virus is detected by isolation in embryonated eggs or by molecular methods for up to four weeks. After, there is usually no virus detection and any IBV found may represent recirculation of the vaccine virus in the flock or the introduction of a new strain. In this study, to evaluate the circulation of the virus in poultry flocks and breeders in the state of Rio Grande do Sul and Mato Grosso do Sul, 240 samples were collected from tracheas and kidneys of birds from 48 flocks, and $(20$ biological samples / 4 flocks) from grandmothers (80 samples/ 16 flocks) and mothers (140 samples/28 flocks) from broilers, which were analyzed in pools of five samples. All animals were vaccinated and samples were collected around 2-48 weeks after vaccination. The presence of IBV was determined with the aid of a polymerase chain reaction "nested" gene-directed protein S1, standardized in this study. From the 48 samples tested, 14 were positive: 5 were from birds vaccinated after less than 4 weeks and 9 were from birds vaccinated more than four weeks should be wild viruses or represent the recirculation of the vaccine virus.
\end{abstract}

Key words: infectious bronchitis of chickens, IBV, nested-PCR, grandmothers, mothers.

\section{INTRODUÇÃO}

$\mathrm{O}$ vírus da bronquite infecciosa (VBI) pertence ao gênero Coronavirus, da família

Instituto de Ciências da Saúde, Universidade Feevale, Rodovia RS-239, 2755, 93352-000, Novo Hamburgo, RS, Brasil. E-mail: fernandors@feevale.br. *Autor para correspondência. 
Coronaviridae e ordem Nidovirales (MONTASSIER et al., 2008). O gênero é separado em três grupos de acordo com suas características genéticas e antigênicas, sendo o VBI pertencente ao grupo 3 (MCKINLEY et al., 2008) e os patógenos desse grupo são exclusivos de aves (JACKWOOD et al., 2003). O vírus é envelopado, de cadeia de RNA de fita única, com simetria helicoidal, pleomórfico, com diâmetro que varia entre 90 a $200 \mathrm{~nm}$, o envelope possui externamente espículas, que lhe conferem um aspecto de coroa, daí a nome Coronavirus (DI FABIO \& ROSSINI, 2000). A infecção acomete aves de ambos os sexos seja na criação para corte, na produção de ovos, nas mais diferentes idades e a doença ocorre em praticamente todas as regiões do mundo onde existe avicultura industrial (DIFABIO \& ROSSINI, 2000; MONTASSIER et al., 2008; LIU et al., 2009). As perdas econômicas estão relacionadas ao comprometimento do estado geral da ave, oriundo da forma respiratória da doença, aos impactos no trato reprodutivo e na qualidade dos ovos. Em poedeiras, pode causar severo declínio na produção e, posteriormente, diminuição do tamanho, da qualidade interna e da casca do ovo (DHINAKAR \& JONES, 1997).

Desde que o VBI foi descrito pela primeira vez por Schalk e Hawn em 1930, muitos sorotipos têm sido identificados pelo mundo (McKINLEY et al., 2008) e novas variantes emergem continuamente, apesar dos programas de vacinação. No Brasil, utilizam-se majoritariamente vacinas utilizando cepas do grupo Massachussets, principalmente H120, seguida de H52. $O$ vírus vacinal pode ser encontrado até quatro semanas após a vacinação, depois disso, se encontrado, pode representar recirculação do vírus vacinal no plantel ou a introdução de uma nova cepa do vírus. Tal fato já foi relatado em diferentes estudos, o vírus vacinal pode ser encontrado em um período de 35 dias após a vacinação (TORO, 2010). Além disso, foi também relatado que amostras vacinais de VBI podem se disseminar não apenas no próprio plantel, mas de um lote vacinado a lotes de aves na vizinhança, tanto em condições experimentais (MATTHIJS et al., 2008), quanto em situações de criação comercial (MATTHIJS et al., 2003). El BOUQDAOUI et al. (2005) demonstraram que, em uma região onde os genótipos circulantes se apresentaram em três linhagens distintas do grupo Mass, vírus com perfil relacionado às cepas vacinais H120 e H52 puderam ser detectados em 17\% dos casos, sendo, provavelmente, relacionados à disseminação de vírus introduzidos pela própria vacinação. Vacinas vivas atenuadas apresentam uma probabilidade de reverter à virulência, o que pode resultar em uma maior propagação do vírus (FARSANG et al., 2002;
MCKINLEY et al., 2008). O presente estudo teve por objetivo detectar a circulação de VBI em plantéis de frangos e reprodutoras por "nested-RT-PCR" em granjas comerciais dos estados do Rio Grande do Sul e Mato Grosso do Sul, Brasil, em diferentes períodos após a vacinação.

\section{MATERIAL E MÉTODOS}

Foram coletadas amostras de traqueia e rim de galinhas em granjas comerciais localizadas no interior do Estado do Rio Grande do Sul e Mato Grosso do Sul, sendo essas amostras constituídas de um conjunto de cinco traqueias e cinco rins para cada plantel (plantéis compostos de 200 a 1000 aves, conforme a categoria amostrada). Foram coletadas amostras de um total de 240 aves pertencentes a 48 plantéis. Os plantéis foram compostos de avós (20 exemplares/4 plantéis), matrizes (80 exemplares/16 plantéis) e frangos de corte (140 exemplares/28 plantéis) (Tabela 1). O trabalho e coletas foram autorizados pelas empresas responsáveis pelas granjas e o projeto aprovado foi realizado seguindo os cuidados éticos estabelecidos pela legislação brasileira.

As amostras foram coletadas nas próprias granjas, sendo identificadas através do preenchimento de um formulário de coleta com as informações referentes à amostra coletada, como a data em que foi realizada a coleta, número do lote, unidade (referente à cidade de origem), tipo (se avó, matriz ou frango de corte) e idade do plantel. Depois de identificadas, as amostras foram armazenadas em sacos plásticos e transportadas refrigeradas dentro de caixas de isopor com gelo e, ao chegar ao laboratório, armazenadas em freezer $-80^{\circ} \mathrm{C}$ para análise posterior. As amostras padrão de VBI H120 e amostras de campo brasileiras, gentilmente cedidas pela Dra. Clarice Weis Arns (Laboratório de Virologia Animal, UNICAMP), com perfis diferenciados, foram utilizadas como controles positivos e para análise do poder discriminatório da nested-RT-PCR.

Neste trabalho, foi usada a técnica de nested-RT-PCR para detectar o gene da região codificante da porção S1 da glicoproteína S (Spike) do VBI e detectar a ocorrência do vírus nos plantéis analisados. O RNA viral foi extraído de tecidos (traqueia e rim) dos exemplares amostrados. A amplificação e identificação do RNA viral foram feitas usando dois conjuntos de iniciadores desenhados neste trabalho, complementares à região do gene da glicoproteína $S$ (fração S1) em um protocolo de nested-RT-PCR. O par de iniciadores usados foi desenhado neste trabalho no primeiro PCR, o qual consiste de oligonucleotídeos 
Tabela 1 - Relação dos plantéis analisados com seus números de registro, cidade de origem, idade da coleta, vacinação e idade após a vacinação.

\begin{tabular}{|c|c|c|c|c|c|}
\hline $\mathrm{N}^{\mathrm{o}}$ registro & Cidade de origem & Tipo do plantel & $\begin{array}{l}\text { Idade na coleta } \\
\quad(\text { sem.) }\end{array}$ & $\begin{array}{l}\text { Idade na vacinação } \\
\text { (sem.) }\end{array}$ & Semanas após a vacinação \\
\hline B1 & Passo Fundo - RS & Frango de corte & 2 & 1 dia & 2 \\
\hline B2 & Montenegro - RS & Frango de corte & 2 & 1 dia & 2 \\
\hline B3 & Salvador do Sul - RS & Matrizeses & 29 & 15 & 14 \\
\hline B4 & Nova Bassano- RS & Matrizes & 42 & 35 & 7 \\
\hline B5 & Estação - RS & Matrizes & 54 & 15 & 39 \\
\hline B6 & Caxias do Sul - RS & Matrizes & 29 & 16 & 13 \\
\hline B7 & Coqueiros do Sul-RS & Matrizes & 29 & 15 & 28 \\
\hline B8 & Mormaço - RS & Matrizes & 41 & 15 & 26 \\
\hline B9 & Nova Bassano & Matrizes & 41 & 35 & 6 \\
\hline B10 & Salvador do Sul & Matrizes & 37 & 16 & 21 \\
\hline B11 & Estação & Matrizes & 46 & 15 & 31 \\
\hline B12 & Nova Bassano & Matrizes & 36 & 15 & 21 \\
\hline B14 & Nova Bassano & Matrizes & 60 & 35 & 25 \\
\hline B15 & Vacaria & Avós & 26 & 15 & 11 \\
\hline B16 & Vacaria & Avós & 26 & 15 & 11 \\
\hline B17 & Caxias do sul & Matrizes & 29 & 16 & 13 \\
\hline B18 & Ipê - RS & Avós & 61 & 15 & 46 \\
\hline B19 & Ipê & Avós & 60 & 15 & 45 \\
\hline B20 & Nova Bassano & Matrizes & 50 & 16 & 34 \\
\hline B22 até B47 (26 lotes) & Montenegro & Frango de corte & 4 & 1dia & 4 \\
\hline B48 & Dourados - MS & Matrizes & 28 & 19 & 10 \\
\hline B49 & Dourados - MS & Matrizes & 66 & 19 & 48 \\
\hline B50 & Laguna Carapã - MS & Matrizes & 41 & 19 & 22 \\
\hline
\end{tabular}

universais flanqueando a região de maior variação do gene S1. O segundo par de iniciadores localiza uma região menos conservada dentro da área amplificada pelo primeiro par de iniciadores, específica de vírus do sorogrupo Massachusetts (Ma). Os oligonucleotídeos que foram usados para amplificar o gene $\mathrm{S}$ estão listados na tabela 2 , sendo que todos foram desenhados usando o programa Oligo Explorer (Genelink, Hawthorn, EUA). O desenho dos primers foi realizado com base em alinhamento de sequências nucleotídicas do Genbank, com os números de acesso M21969 para a amostra D207, M21970 e AF352315, representando amostras do sorogrupo Mass.

Para realizar a extração de RNA, depois de descongelados, os órgãos foram macerados e diluídos em $600 \mu \mathrm{L}$ de PBS, sendo em seguida centrifugados a 10.000rpm por 5 minutos e o sobrenadante transferido para novo tipo eppendorf. O RNA viral foi extraído usando kit Virus DNA/RNA Mini Kit (Invitek - Invisorb, Alemanha), seguindo estritamente as instruções do fabricante. A síntese do cDNA foi feita utilizando kit High Capacity cDNA Synthesis (Applied Biosystems), conforme instruções do fabricante, utilizando oligonucleotídeos aleatórios. Para a PCR, $3 \mu \mathrm{L}$ do cDNA obtido, $20 \mathrm{pmol}$ de cada iniciador, $12,5 \mu \mathrm{L}$ de Mix $2 \mathrm{X}$ para PCR (LGCBio, Cotia, SP), 0,2mM de cada dNTP, e água para o volume final de $25 \mu \mathrm{L}$. Para amplificação, foi montado um sistema de touchdown (TD) PCR, composto por um ciclo de desnaturação inicial $\left(95^{\circ} \mathrm{C}\right.$, $8 \mathrm{~min})$, seguido 35 ciclos de desnaturação $\left(94^{\circ} \mathrm{C}, 1 \mathrm{~min}\right)$; anelamento inicial a $58^{\circ} \mathrm{C}$ decrescendo $0,5^{\circ} \mathrm{C}$ a cada ciclo (1 min) e extensão $\left(72^{\circ} \mathrm{C}, 1 \mathrm{~min}\right)$; e uma extensão final $\left(72^{\circ} \mathrm{C}, 10 \mathrm{~min}\right)$. $\mathrm{O}$ mesmo programa foi utilizado nos dois passos da PCR. Previamente aos ensaios com amostras coletadas no campo, a sensibilidade analítica da técnica foi determinada pelo teste de diluições decimais seriadas de uma vacina comercial contendo 1000 doses e cada diluição, extraída de forma independente em triplicata. Foi observado um limiar de detecção da ordem de 0,001 dose de vírus vacinal (que corresponde a $1 \mathrm{pfu}$ do vírus, segundo informações de bula). Os produtos finais das amplificações foram submetidos à eletroforese em gel de agarose a $2 \% \mathrm{e}$, em seguida, os géis foram corados com $0,5 \mu \mathrm{g} \mathrm{mL}^{-1}$ do corante atóxico BlueGreen (LGCBio, Cotia, SP) e os resultados visualizados sob luz UV. 
Tabela 2 - Oligonucleotídeos usados no presente estudo para amplificação de fragmentos específicos do gene S1 de vírus VBI do sorogrupo Massachusetts.

\begin{tabular}{lcccc}
\hline Oligonucleotídeo & \multicolumn{1}{c}{ Sequência } & Posição no gene & TM ${ }^{\circ} \mathrm{C}$ & Amplicom (pb) \\
\hline H120Fw & 5'-GCTGGTGGACCTATAACTT-3' & 574 & 57,4 & 326 \\
H120Rev & 5'-ACAACTTGGGTGGTAAGAC-3' & 899 & & \\
InternoFw1 & 5'-GCGGGAAGTTAAAGCATTGG-3' & 606 & 58,5 & 251 \\
InternoRev1 & 5'-CTGTGTTAGGGGTAGCAT-3' & 856 & & \\
\hline
\end{tabular}

\section{RESULTADOS}

Das 48 amostras analisadas, 14 foram positivas para VBI, dentre elas, cinco pertenciam a plantéis de matrizes, quatro de plantéis de avós e cinco pertenciam a plantéis de frangos de corte (Tabela 3). Das cinco amostras positivas de matrizes, duas (B6 e B17) eram oriundas da cidade de Caxias do Sul, sendo ambas coletadas de animais com 29 semanas de idade. Estes receberam a vacinação com vírus H120 vivo 13 semanas antes. Uma amostra de plantel de matrizes, proveniente da cidade de Salvador do Sul, (B10) também se montrou positiva na 21 semanas após a vacinação. O mesmo vale para as quatro amostras positivas de avós (B15 e B16), as quais eram oriundas da cidade de Vacaria, ambas foram coletadas com 26 semanas de idade, 11 semanas após a vacinação, que ocorreu quando tinham a idade de 15 semanas. As outras duas amostras são provenientes da cidade de Ipê e possuem os números de registro B18 e B19. Foram coletadas com 61 e 60 semanas de idade, tendo ambas sido vacinadas com 15 semanas, ou seja, foram coletadas 46 e 45 semanas após a vacinação, respectivamente.

Todas as cinco amostras positivas de plantéis de frangos de corte (B24, B25, B37, B42 e B47) eram provenientes da cidade de Montenegro, provinham de animais com 4 semanas de idade e a vacinação ocorreu no primeiro dia de vida.

\section{DISCUSSÃO}

A presença do VBI pôde ser detectada em períodos de 4 a 46 semanas após a vacinação. A detecção de VBI no período de até 4 semanas após à vacinação pode estar relacionada à excreção e circulação dos vírus vacinais nos plantéis, conforme

Tabela 3 - Plantéis positivos para detecção molecular para amplificação de fragmentos específicos do gene S1 de vírus VBI do sorogrupo Massachusetts.

\begin{tabular}{|c|c|c|c|c|c|}
\hline $\mathrm{N}^{\mathrm{o}}$ registro & Origem & Tipo plantel & $\begin{array}{l}\text { Idade na coleta } \\
\text { (semanas) }\end{array}$ & $\begin{array}{c}\text { Vacinação com H120 } \\
\text { (semanas) }\end{array}$ & $\begin{array}{c}\text { Semanas após a vacinação } \\
\text { com H120 }\end{array}$ \\
\hline B6 & Caxias do sul & Matrizes & 29 & 16 & 13 \\
\hline B10 & Salvador do Sul & Matrizes & 37 & 16 & 21 \\
\hline B14 & Nova Bassano & Matrizes & 60 & 35 & 25 \\
\hline B15 & Vacaria & Avós & 26 & 15 & 11 \\
\hline B16 & Vacaria & Avós & 26 & 15 & 11 \\
\hline B17 & Caxias do sul & Matrizes & 29 & 16 & 13 \\
\hline B18 & Ipê & Avós & 61 & 15 & 46 \\
\hline B19 & Ipê & Avós & 60 & 15 & 45 \\
\hline B20 & Nova Bassano & Matrizes & 50 & 16 & 34 \\
\hline B24 & Montenegro & Frango de corte & 31 dias & $1 \mathrm{dia}$ & 4 \\
\hline B25 & Montenegro & Frango de corte & 31 dias & 1 dia & 4 \\
\hline B37 & Montenegro & Frango de corte & 29 dias & $1 \mathrm{dia}$ & 4 \\
\hline B42 & Montenegro & Frango de corte & 30 dias & $1 \mathrm{dia}$ & 4 \\
\hline B47 & Montenegro & Frango de corte & 31 dias & $1 \mathrm{dia}$ & 4 \\
\hline
\end{tabular}


demonstrado em relatos anteriores, obtidos do monitoramento da excreção do vírus vacinal em lotes comerciais (MATTHIJS et al., 2003). Passado esse período, os resultados positivos encontrados devem ser relacionados à presença de variantes ou ainda a uma nova circulação do vírus vacinal nos plantéis (TORO, 2010). Ainda há que ressaltar que DERGHAM et al. (2009) detectaram genomas de VBI por RT-PCR em plantéis de galinhas que haviam sido vacinados logo antes de apresentarem sinais clínicos de doenças respiratórias. As vacinas vivas atenuadas conferem melhor imunidade local no trato respiratório. Entretanto, há o risco de patogenicidade residual, reversão de virulência e persistência nos plantéis por períodos prolongados (BIJLENGA et al., 2004; McKINLEY et al., 2008).

A variabilidade das amostras de VBI é alta e genótipos diversos têm sido reportados no Brasil. Montassier et al. (2008) descreveram 5 genótipos diferentes no país, sendo eles: M, A, B, C e D, oriundos das regiões Sudeste e Sul do país. Conforme afirmam ABREU et al. (2006), os isolados de VBI encontrados no Brasil apresentaram grande diversidade genética, independentemente da data de isolamento, antes e após a aprovação oficial da vacinação no Brasil (1980), indicando uma diversificação natural do VBI a despeito das vacinas presentemente utilizadas.

Os resultados obtidos demonstram que o VBI circulou nos plantéis de avós, matrizes e frangos de corte estudados em períodos variados após a vacinação, tanto dentro das quatro semanas em que ainda pode haver circulação de vírus vacinal ou mesmo após, quando seria provável a circulação de vírus selvagens. Especialmente no caso de avós e matrizes, os dados apontam para a possível ocorrência de amostras de campo similares aos vírus vacinais ou ainda a nova circulação do vírus vacinal, uma vez que o intervalo de tempo entre a vacinação e a coleta foi, para todas as matrizes, superior a quatro semanas. A eficácia das vacinas vivas ainda é bastante discutida, além do mais, de acordo com CAVANAGH (2007), as galinhas não respondem uniformemente à vacinação contra VBI. Em adição, a proteção conferida pela vacinação é de curta duração, o início do declínio dessa imunidade protetora começa a aparecer 9 semanas após a imunização (MATTHIJS et al., 2003). Outro fato curioso a destacar foi a não detecção de vírus em aves vacinadas há apenas duas semanas (planteis B1 e B2). Esse fato pode estar relacionado a práticas inadequadas no processo de vacinação e aponta que um monitoramento das campanhas de vacinação deve ser adotado, especialmente onde há o relato prévio de manejo deficiente.

\section{AGRADECIMENTOS}

O presente trabalho foi realizado com recursos do Conselho Nacional de Desenvolvimento Científico e Tecnológico (CNPq). FRS é bolsista de produtividade do CNPq.

\section{REFERÊNCIAS}

ABREU, J.T. et al. Molecular analysis of Brazilian infectious bronchitis field isolates by reverse transcription-polymerase chain reaction, restriction fragment length polymorphism, and partial sequencing of the $\mathrm{N}$ gene. Avian Diseases, v.50, n.4, p.494-501, 2006. Disponível em: <http://dx.doi.org/10.1637/ 7525-030706R.1>. Acesso em: 02 fev. 2012. doi: 10.1637/ 7525-030706R.1.

BIJLENGA, $\mathrm{G}$ et al. Development and use of the $\mathrm{H}$ strain of avian infectious bronchitis virus from the Netherlands as a vaccine: a review. Avian Pathology, v.33, n.6, p.550-557, 2004. Disponível em: <http://dx.doi.org/10.1080/03079450400013154>. Acesso em: 02 fev. 2012. doi: 10.1080/03079450400013154.

BRONZONI, R.V.M. et al. Detection of infectious bronchitis virus and specific anti-viral antibodies using a concanavalin $\mathrm{A}$ sandwich - ELISA. Viral Immunology, v.18, n.3, p.569-578, 2005. Disponível em: <http://dx.doi.org/10.1089/vim. 2005.18.569>. Acesso em: 01 fev. 2012. doi: 10.1089/ vim.2005.18.569.

CAVANAGH, D. Coronavirus avian infectious bronchitis virus. Veterinary Research, v.38, n.2, p.281-297, 2007. Disponível em: 〈http://dx.doi.org/10.1051/vetres:2006055>. Acesso em: 01 fev. 2012. doi: 10.1051/vetres:2006055.

DERGHAM, A.R. et al. Infectious bronchitis virus in Jordanian chickens: Seroprevalence and detection. Canadian Veterinary Journal, v.50, n.4, p.77-80, 2009. Disponível em: <http:// www.ncbi.nlm.nih.gov/pmc/articles/PMC2603658/>. Acesso em: 30 jan. 2012.

DHINAKAR, R.G.; JONES, R.C. Infectious bronchitis virus: Immunopathogenesis of infection in the chicken. Avian Pathology, v.26, n.4, p.677-706, 1997. Disponível em: <http:/ /dx.doi.org/10.1080/03079459708419246>. Acesso em: 01 fev. 2012. doi: 10.1080/03079459708419246.

DI FÁBIO, J.; ROSSINI, L.I. Bronquite infecciosa das galinhas. In: BERCHIERI, A.J.; MACARI, M. Doenças das aves. 3.ed. Campinas: FACTA, 2000. p.293-300.

EL BOUQDAOUI, M. et al. Genetic grouping of nephropathogenic avian infectious bronchitis virus isolated in Morocco. International Journal of Poultry Science, v.4, n.9, p.721-727, 2005. Disponível em: Disponível em: <http:/ /dx.doi.org/10.3923/ijps.2005.721.727>. Acesso em: 22 set. 2012. doi: 10.3923/ijps.2005.721.727.

FARSANG, A. et al. Molecular epizootiology of infectious bronchitis virus in Sweden indicating the involvement of a vaccine strain. Avian Pathology, v.31, n.3, p.229-236, 2002. Disponível em: <http://dx.doi.org/10.1080/03079450220136530>. Acesso em: 02 fev. 2012. doi: 10.1080/03079450220136530.

JACKWOOD, M.W. et al. Detection of infectious bronchitis virus by real-time reverse transcriptase-polymerase chain 
reaction and identification of a quasispecies in the Beaudette strain. Avian Diseases, v.47, n.3, p.718-724, 2003. Disponível em: 〈http://dx.doi.org/10.1637/6075>. Acesso em: 30 jan. 2012. doi: 10.1637/6075.

LIU, S. et al. Evaluation of the protection conferred by commercial vaccines and attenuated heterologous isolates in China against the CK/CH/LDL/97I strain of infectious bronchitis coronavirus. Veterinary Journal, v.179, n.1, p.130-136, 2009. Disponível em: <http://dx.doi.org/10.1016/j.tvj1.2007. 08.018>. Acesso em: 30 jan. 2012. doi: 10.1016/ j.tvj1.2007.08.018.

MATTHIJS, M.G.R. et al. Ability of Massachusetts-type infectious bronchitis virus to increase colibacillosis susceptibility in commercial broilers: a comparison between vaccine and virulent virus. Avian Pathology, v.32, n.5, p.473-481, 2003. Disponível em: <http://www.tandfonline.com/doi/abs/10.1080/ 0307945031000154062>. Acesso em: 22 set. 2012. doi: 10.1080/0307945031000154062.

MATTHIJS, M.G.R. et al. Transmissibility of infectious bronchitis virus $\mathrm{H} 120$ vaccine strain among broilers under experimental conditions. Avian Diseases, v.52, n.3, p.461466, 2008. Disponível em: 〈http://dx.doi.org/10.1637/8204010708-Reg.1>. Acesso em: 22 set. 2012. doi: 10.1637/8204010708-Reg.1.

MCKINLEY, E.T. et al. Avian coronavirus infectious bronchitis attenuated live vaccines undergo selection of subpopulations and mutations following vaccination. Vaccine, v.26, n.10, p.1274-1284, 2008. Disponível em: <http://dx.doi.org/ 10.1016/j.vaccine.2008.01.006>. Acesso em: 02 fev. 2012. doi: 10.1016/j.vaccine.2008.01.006.
MENDONÇA, J.F.P. et al. Bronquite infecciosa das galinhas: conhecimentos atuais, cepas e vacinas no Brasil. Ciência Rural, v.39, n.8, p.2559-2566, 2009. Disponível em: <http:/ /dx.doi.org/10.1590/S0103-84782009005000195>. Acesso em: 01 fev. 2012. doi: 10.1590/S0103-84782009005000195.

MONTASSIER, M. de F. et al. Genetic grouping of avian infectious bronchitis virus isolated in Brazil based on RT-PCR/ RFLP analysis of the $\mathrm{S} 1$ gene. Pesquisa Veterinária Brasileira, v.28, n.3, p.190-194, 2008. Disponível em: <http:/ /dx.doi.org/10.1590/S0100-736X2008000300011>. Acesso em: 02 fev. 2012. doi: 10.1590/S0100-736X2008000300011.

OKINO, C.H. et al. Infectious bronchitis virus: detection and vaccine strain differentiation by semi-nested RT-PCR. Revista Brasileira de Ciência Avícola, v.7, n.1, p.59-66, 2005. Disponível em: <http://dx.doi.org/10.1590/S1516-635X2005000100010>. Acesso em: 02 fev. 2012. doi: 10.1590/S1516-635X2005000100010.

SMATI R. et al. Molecular characterization of three new avian infectious bronchitis virus (IBV) strains isolated in Quebec. Virus Genes, v.25, n.1, p.85-93, 2002. Disponível em: <http:/ /www.springerlink.com/content/h966419440035826/>. Acesso em: 01 fev. 2012. doi: 10.1023/A:1020178326531.

TORO H. Infectious bronchitis virus: dominance of ArkDPItype strains in the United States broiler industry during the last decade. Revista Brasileira de Ciência Avícola, v.12, n.2, p.79-86, 2010. Disponível em: <http://dx.doi.org/10.1590/ S1516-635X2010000200002>. Acesso em: 22 set. 2012. doi: 10.1590/S1516-635X2010000200002. 